\title{
Um Leilão à Prova de Estratégia para o Compartilhamento de Viagens Dinâmico com Múltiplos Passageiros*
}

\author{
Leonardo Y. Schwarzstein ${ }^{1}$, Flávio K. Miyazawa ${ }^{1}$, Rafael C. S. Schouery ${ }^{1}$ \\ ${ }^{1}$ Instituto de Computação - Universidade Estadual de Campinas (UNICAMP) \\ Av. Albert Einstein, 1251 - 13083-852 - Campinas - SP - Brazil \\ leoyvens@gmail.com, \{fkm,schouery\}@ic.unicamp.br
}

\begin{abstract}
Dynamic ridesharing systems arrange rides between drivers and passengers on short notice. In this paper, we propose an auction that selects passengers to be served and define prices they should be charged so that prices are fair for drivers and passengers while providing profit for the company.
\end{abstract}

Resumo. Sistemas de compartilhamento de viagens dinâmico designam passageiros a motoristas em curto prazo. Neste artigo, propomos um leilão que seleciona passageiros a serem servidos e define preços que estes devem pagar, de maneira justa para motoristas e passageiros, provendo lucro para a empresa.

\section{Introdução}

No contexto da mobilidade urbana, o compartilhamento de viagens ocorre quando uma viagem em um veículo pessoal é compartilhada por pessoas com trajetos similares, no intuito de dividir custos. Isto motiva o problema do compartilhamento de viagens dinâmico, que, em curto prazo, designa passageiros a motoristas e determina os preços a serem cobrados. Leilões são estudados como um mecanismo para solucionar este problema.

Duas propriedades se destacam neste contexto. Um leilão é à prova de estratégia se o passageiro obtém o maior ganho possível ao reportar como lance o seu real valor para a viagem. Ou seja, o passageiro não consegue manipular o leilão individualmente para alterar o resultado do leilão a seu favor. Um leilão tem um orçamento balanceado quando o preço pago ao motorista sempre cobre os custos para transportar os passageiros.

Trabalhos relacionados. Existem dois trabalhos sobre leilões para compartilhamento de viagens dinâmico. O primeiro [Kamar and Horvitz 2009] propõe um sistema para múltiplos motoristas baseado no leilão Vickrey-Clark-Groves (VCG) [Vickrey 1961] que, por usar heurísticas que garantem melhor desempenho computacional, deixa de garantir a propriedade de ser à prova de estratégia. O segundo [Kleiner et al. 2011] considera um leilão à prova de estratégia (uma adaptação do leilão de segundo preço [Vickrey 1961]) para um único motorista e um único passageiro. Um levantamento [Furuhata et al. 2013] cita desafios nestes trabalhos, que são garantir a propriedade de ser à prova de estratégia e permitir múltiplos passageiros por viagem. De fato, o leilão que propomos atende estas duas propriedades. A formulação é baseada no Dial-A-Ride-Problem (DARP), como modelado em [Cordeau 2003].

*Parcialmente financiada pela Fundação de Amparo à Pesquisa do Estado de São Paulo (FAPESP), processo 2013/21744-8 e pelo Conselho Nacional de Desenvolvimento Científico e Tecnológico (CNPq), processo 311499/2014-7. 
Resultados. Neste artigo, propomos um leilão, chamado leilão de segundo excedente mínimo, para o compartilhamento de viagens dinâmico com motorista único e múltiplos passageiros servidos. Apesar de aplicações reais envolverem múltiplos motoristas, estudar o caso do motorista único é interessante como um subproblema do caso geral, além de trazer novas ideias para atacar o problema mais geral. Provamos que o leilão é à prova de estratégia e tem um orçamento balanceado. Estas propriedades se mantêm mesmo que a solução computacional não seja exata, uma característica importante para poder resolver o problema na prática. O leilão pode receber mais que o necessário para pagar o custo do motorista sendo que o excedente é o lucro da empresa. Como o leilão é genérico em certos critérios, propomos uma variação que busca maximizar o lucro da empresa. Os experimentos indicam a viabilidade do leilão proposto.

\section{Modelo e Notação}

No modelo que consideramos, temos um único motorista e um conjunto de passageiros. Nos referimos a um passageiro qualquer como passageiro $i$. Uma entrada do problema é representada por um grafo completo onde os vértices são os pontos de partida e de chegada do motorista e os pontos de coleta e entrega dos passageiros. Os pontos de coleta possuem uma janela de tempo onde a coleta é válida. Cada aresta possui um custo e um tempo para percorrê-la. Tanto o motorista como os passageiros possuem um tempo máximo de viagem. O veículo tem uma capacidade máxima no número de pessoas que pode transportar. Estas são as restrições de roteamento, inspiradas no modelo DARP [Cordeau 2003] e buscam tornar a viagem conveniente para todos.

O maior valor que o passageiro $i$ pode pagar para ser servido pelo motorista é dado por $v_{i}$. Como esta informação não é conhecida pelo sistema, cada passageiro fornece um número não-negativo $b_{i}$ como lance que representa o seu valor (porém, ele pode reportar $b_{i} \neq v_{i}$ se assim o desejar). O leilão deve determinar o conjunto de passageiros a ser servido pelo motorista, denotado por $P^{*}$, e o preço pago por cada passageiro servido, denotado $p_{i}$. Se $i \notin P^{*}$ então o passageiro $i$ não é servido e $p_{i}=0$. Definimos a utilidade de um passageiro $i$ como $u_{i}=v_{i}-p_{i}$ se $i \in P^{*}$ e $u_{i}=0$ se $i \notin P^{*}$. Um leilão é à prova de estratégia se, para todo passageiro $i$, nenhum valor de $b_{i}$ resulta em uma utilidade maior para $i$ do que a utilidade obtida fazendo $b_{i}=v_{i}$. Isto é, o passageiro $i$ não obtém vantagens mentindo.

O custo do motorista para servir um conjunto $P$ de passageiros é denotado por $c_{m}(P)$. Tal custo não depende dos lances. Definimos que um leilão tem um orçamento balanceado se $\sum_{i \in P^{*}} p_{i} \geq c_{m}\left(P^{*}\right)$. Ou seja, o preço total cobrado dos passageiros é suficiente para pagar o custo para servi-los.

\section{Leilão de Segundo Excedente Mínimo}

Esta seção detalha o leilão de segundo excedente mínimo e suas propriedades. Primeiro, determinam-se os conjuntos que participam do leilão, depois, qual será servido pelo motorista e o preço a ser pago por cada passageiro. Paga-se ao motorista o valor $c_{m}\left(P^{*}\right)$, e o restante do pagamento fica para a empresa, que gerencia o sistema. Participam do leilão apenas conjuntos para os quais existe uma rota que respeita as restrições de roteamento e serve apenas os passageiros do conjunto. Caso haja mais de uma rota viável, é escolhida a mais curta. Denotamos a família de conjuntos participantes do leilão por $\mathcal{B}$. Se um passageiro $i$ estiver simultaneamente em dois conjuntos participantes, o leilão poderia não ser 
à prova de estratégia. Para lidar com essa situação, tomaremos $\mathcal{B}$ como uma partição do conjunto de passageiros, restringindo quais conjuntos participam do leilão. Como existem várias maneiras de se construir $\mathcal{B}$, apresentamos um possível critério na Seção 4.

\subsection{Determinando o Conjunto Servido e a Precificação}

Nesta seção descrevemos a escolha do conjunto $\mathcal{B}$ a ser servido e o preço para cada passageiro servido. Parece natural servir um conjunto de passageiros com lances altos. Porém isto pode resultar em um benefício baixo para a empresa e para o motorista caso o custo de servir este conjunto também seja alto. Por isso, consideramos o excedente do lance em relação ao custo ao escolher os passageiros servidos. A seguir, formalizamos as definições de custo do passageiro e excedente do passageiro.

Dado $P \in \mathcal{B}$, o custo para cada passageiro $i \in P$, denotado por $c_{i}$, é escolhido de forma que $\sum_{i \in P} c_{i}=c_{m}(P)$. Ou seja, o custo do motorista para servir o conjunto é dividido entre os passageiros. Esta divisão pode ser feita através de qualquer critério que não dependa dos lances como, por exemplo, uma divisão uniforme. $\mathrm{O}$ excedente de $i$, denotado $s_{i}$, é definido como $s_{i}=b_{i}-c_{i}$.

Garantimos o orçamento balanceado, impondo que $p_{i} \geq c_{i}$ para todo $i \in P^{*}$. Assim o preço para um passageiro servido será o custo $c_{i}$ mais uma parcela de lucro para a empresa. Esta parcela será igual para todos os passageiros servidos. Definimos o excedente mínimo de um conjunto $P$, denotado por $s_{\min }(P)$, como $s_{\min }(P)=\min \left\{s_{i} \mid i \in P\right\}$. Com isso, escolhemos $P^{*} \in \mathcal{B}$ tal que $s_{\min }\left(P^{*}\right)=\max \left\{s_{\min }(P) \mid P \in \mathcal{B}\right\}$, ou seja, o conjunto servido é aquele com o maior excedente mínimo, sendo que se este valor for negativo, então ninguém é servido.

Após escolher $P^{*}$, determinamos $p_{i}$ para $i \in P^{*}$. Aqui nos inspiramos no leilão de segundo preço, e definimos o segundo excedente mínimo, denotado por $s_{2}$, como $s_{2}=\max \left\{\max \left\{s_{\min }(P) \mid P \in \mathcal{B}, P \neq P^{*}\right\}, 0\right\}$. Ou seja, $s_{2}$ é o segundo maior excedente mínimo, ou 0 caso este seja negativo. Por fim, definimos $p_{i}=c_{i}+s_{2}$ para todo $i \in P^{*}$, de modo que $p_{i}$ não depende de $b_{i}$. A parcela $c_{i}$ será paga ao motorista e a parcela $s_{2}$ será paga para a empresa.

\subsection{Propriedades do Leilão de Segundo Excedente Mínimo}

Teorema 3.1. O leilão de segundo excedente mínimo tem o orçamento balanceado.

Demonstração. Como $s_{2} \geq 0$, temos $\sum_{i \in P^{*}}\left(c_{i}+s_{2}\right)=c_{m}\left(P^{*}\right)+\left|P^{*}\right| s_{2}$ e da definição de $p_{i}$ para $i \in P^{*}$ conclui-se $\sum_{i \in P^{*}} p_{i} \geq c_{m}\left(P^{*}\right)$.

Teorema 3.2. O leilão de segundo excedente mínimo é a prova de estratégia.

Demonstração. Considere um passageiro $i$. Se o passageiro $i$ dá o lance $b_{i}=x$, então seja $u_{x}$ sua utilidade, $p_{x}=c_{i}+s_{2}^{x}$ o seu preço caso seja servido, $P_{x}^{*}$ o conjunto servido e $s_{2}^{x}$ o segundo excedente mínimo. Note que $u_{v_{i}} \geq 0$, já que um passageiro nunca paga mais do que o seu lance no leilão de segundo excedente mínimo. Se $i \notin P_{x}^{*}$ então $u_{x}=0$ e $u_{v_{i}} \geq u_{x}$. Se $i \in P_{x}^{*}$ e $i \in P_{v_{i}}^{*}$ então $u_{x}=u_{v_{i}}$ pois $p_{i}$ não depende do lance de $i$. Se $i \in P_{x}^{*}$ e $i \notin P_{v_{i}}^{*}$ então quando $b_{i}=v_{i}$ o excedente de $i$ é o mínimo do seu conjunto $\log 0 v_{i}-c_{i} \leq s_{\min }\left(P_{v_{i}}^{*}\right)$. Quando $b_{i}=x$ o excedente de $i$ supera $s_{\min }\left(P_{v_{i}}^{*}\right)$ fazendo $s_{\text {min }}\left(P_{v_{i}}^{*}\right)=s_{2}^{x}$. Substituindo obtemos $v_{i}-c_{i} \leq s_{2}^{x}, \log v_{i} \leq p_{i}^{x}$ e $u_{x} \leq 0 \leq u_{v_{i}}$. 


\section{Experimentos Computacionais}

Geramos entradas em um mapa real de aproximadamente 100 quilômetros quadrados do centro da cidade de São Paulo, distribuindo os vértices de maneira uniformemente aleatória. Por simplicidade, dividimos o custo igualmente entre os passageiros, ou seja, $c_{i}=c_{m}(P) /|P|$.

A operação de maior custo computacional é construir $\mathcal{B}$. O critério pode ser qualquer desde que não considere os lances, caso contrário poderia violar a propriedade de ser à prova de estratégia. Nos experimentos utilizamos um algoritmo que minimiza, de maneira gulosa, o custo por passageiro. A cada iteração do algoritmo o conjunto com menor custo por passageiro é adicionado, até não ser possível adicionar mais conjuntos. Implementamos este algoritmo de maneira exata utilizando programação linear inteira e o resolvedor Gurobi. Limitamos o número máximo de passageiros servidos a 4. Em um computador Intel Core i7 2,7 GHz, a implementação obteve solução para uma entrada de 20 passageiros em 10 segundos e para uma entrada de 100 passageiros em 10 minutos. Isto demonstra que o problema é tratável em tempo prático, porém para entradas maiores é necessário implementar heurísticas para atender aos requisitos de um sistema dinâmico.

\section{Conclusão}

O leilão de segundo excedente mínimo combina as propriedades desejáveis de ser à prova de estratégia e ter um orçamento balanceado, respondendo a questões em aberto na literatura. O arcabouço teórico é robusto pois permite liberdade nos critérios de divisão do custo e de escolha dos conjuntos participantes. O leilão é permissivo em relação a implementação pois o uso de heurísticas no passo mais computacionalmente custoso (construir $\mathcal{B}$ ) não prejudica as propriedades teóricas. Isto é uma vantagem sobre o leilão VCG que requer implementações exatas. Os experimentos estão em fase inicial e pretendemos fazer experimentos comparativos com o leilão VCG, bem como implementar e analisar a performance de heurísticas. As principais limitações do leilão são a restrição a um único motorista e a restrição de que $\mathcal{B}$ deve particionar o conjunto de passageiros. $\mathrm{O}$ desafio futuro mais interessante é generalizar o leilão para múltiplos motoristas.

\section{Referências}

Cordeau, J.-f. (2003). A Branch-and-Cut Algorithm for the Dial-a-Ride Problem. Operations Research, 54:573-586.

Furuhata, M., Dessouky, M., Ordonez, F., Brunet, M.-E., Wang, X., and Koenig, S. (2013). Ridesharing: The state-of-the-art and future directions. Transportation Research Part B: Methodological, 57:28-46.

Kamar, E. and Horvitz, E. (2009). Collaboration and Shared Plans in the Open World: Studies of Ridesharing. In Proceedings of the 21th International Joint Conference on Artificial Intelligence, pages 187-194.

Kleiner, A., Nebel, B., and Ziparo, V. A. (2011). A Mechanism for Dynamic Ride Sharing Based on Parallel Auctions. In Proceedings of the 22th International Joint Conference on Artificial Intelligence, pages 266-272.

Vickrey, W. (1961). Counterspeculation, Auctions, and Competitive Sealed Tenders. The Journal of Finance, 16(1):8-37. 